\title{
What is the DSCAA?
}

The Dental Schools Council Assessment

Alliance (DSCAA) was formed in 2015 and

reports to the Dental Schools Council.

The DSCAA has three aims:

1. To form a partnership aimed at improving undergraduate assessment practices through collaboration between dental schools within the UK and Ireland

2. To develop and provide evidence-based guidance to further enhance and reinforce undergraduate assessment within the UK and Ireland

3. To develop a shared assessment bank of high-quality items in a variety of formats for use by the contributing schools.

The committee comprises up to two staff members per UK or Irish dental school, and should ideally include the Assessment Lead (or person responsible for assessment) for the school they are representing. The committee is led by a Chair and Vice-Chair. Meetings are held twice per year (March and October) and rotate round member schools.

The DSCAA has carried out research on many aspects of undergraduate dental assessment on topics including: 'The assessment load for staff and students,' 'How schools deal with a student's extenuating circumstances', 'Measures schools have implemented to improve feedback to students', and 'How schools recruit external examiners'. Results of this research are then shared with participating schools and it is hoped that they will form the basis of future peer-reviewed publications.

The DSCAA has also created a national database of dental external examiners. This voluntary database contains details of academic and clinical staff who are already (or aspire to be) external examiners for all undergraduate, postgraduate and hygiene and therapy programmes throughout the UK and Ireland. As this database expands, it will bring benefits both to schools and individuals. Firstly, to schools by providing a database of potential academics whom they may approach when looking to appoint a new external examiner. This is particularly beneficial when trying to seek external examiners for very specialist subject areas. Secondly, for individuals who wish to take on such a role, it allows them to promote their profile to all schools. For both parties, it removes the 'word of mouth' approach to finding appropriate academics.

The DSCAA can be contacted via dscaa. contact@gmail.com.

\section{A new helpline for dentists in crisis}

\section{Jeremy Cooper of Confidental writes:}

In 2017, I met a colleague in my local gym.

He was distraught, as a friend of his had taken his own life.

I never knew his friend, we'll call him Steve, but I listened to this practitioner's grief at losing his friend. I remember clearly, one sentence he said: 'I wish I had done more to help him!'

He was referring to the fact that Steve had a number of issues including some with the GDC. There are similar tragic cases replicated throughout the $\mathrm{UK}$, as the profession is well aware.

I have been fortunate in avoiding mental health problems; however, like others, have suffered issues that cause stress arising from patient complaints through to litigation, problems with 'big brother' (eg NHS, GDC, $\mathrm{CQC}$ ), financial and personal issues. These all affect each and every one of us at some time or another.

A few weeks after hearing about Steve, I approached a large multinational corporation involved in dentistry and healthcare and subsequently emailed them, asking whether they would financially support the formation of a helpline for dentists in crisis. They were sympathetic, although they could not offer help, and I therefore decided on another plan.
In early 2018, I called upon many

organisations including the BDA, GDC, FGDP, BDIA, Henry Schein, DP, DDU, MDDUS, BDA Benevolent Fund, Dentists' Health Support Trust, GDP(UK) and a few well known dentists and asked them to attend a meeting in London. MDDUS kindly hosted the well-attended meeting. We heard from organisations such as Lawcare who already provide similar services to solicitors. I wanted to find out whether there was a similar need for a helpline in dentistry.

Following posting on Mental Dental FB group and discussion on the GDPUK website, that question was answered unequivocally with many hundreds of people acknowledging the need for a helpline.

A group of Trustees comprising myself, Lauren Harrhy, Jenny Pinder and Keith Hayes was formed, and a Constitution written. We have now applied for Charity Incorporated Organisation status as well as delivering five volunteer training sessions with the help of the Samaritans, Mind, Relate, Help Line Partnership, Customer 1st training, Dentists Health Support Trust, Joanna Taylor and Janine Brookes MBE. We are grateful to have received presentations also from the GDC, the CQC and the NHS.

We now have 24 trained and dedicated volunteers who help us to deliver Confidental as a $24 / 7$, dentist to dentist, free and nonjudgemental listening helpline. All volunteers are supported by the Confidental trustees and have access to organisations through an updated Resources List to organisations who generously provide their expert services on an initial pro bono basis.

In the near future we will continue to hold training sessions and to extend this to webinars to ensure all volunteers have an updated understanding about regulators, regulations, indemnity, complaints handling and all those things that go bump in the night and leave us lying awake and worried.

Confidental has been sponsored by RightPath4 Ltd, the Wesleyan Foundation and Cumbria LDC.

We are also grateful to Dental Focus for providing and updating our website and of course to our wonderful professional and caring volunteers, without whom none of this would have been possible.

If anyone is interested to help, whether as a volunteer or by way of funding, they can contact Confidental by emailing any of the Trustees at: jeremycooper@jeremycooper.co.uk laurenellie1985@aol.com jenniferpinder1@icloud.com keithhayes22@gmail.com. 